\title{
Viscosity Behavior of Poly(vinylamine) and Swelling-Contraction Phenomenon of Its Gel
}

\author{
Shiro KobaYASHI, ${ }^{*}$ Kyung-Do SUH, Yukio SHIROKURA, \\ and Tomochika FUJIOKA \\ Department of Molecular Chemistry and Engineering, \\ Faculty of Engineering, Tohoku University, \\ Aoba, Sendai 980, Japan
}

(Received March 28, 1989)

\begin{abstract}
The reduced viscosity of high molecular weight poly(vinylamine) (PVAm) depends greatly on $\mathrm{pH}$, ionic strength, and heavy-metal ion concentration. The reduced viscosity of PVAm shows a maximum at $\mathrm{pH} \approx 3$ in the case of the ionic strength $\mu=0(\mathrm{KCl})$ : in the region of $\mathrm{pH}<3$ the viscosity decreased abruptly and the change of $\mathrm{pH}$ to the basic region also brought about a decrease of the viscosity. A similar tendency was observed in the presence of a salt $\mathrm{KCl}(\mu=0.01$, 0.1 and 1.0). A PVAm gel was prepared to apply these behaviors for a chemo-mechanical material. The gel shows a good response with respect to the changes of $\mathrm{pH}$, ionic strength, and cupric ion concentration. In addition, a phenomenon of phase transition is observed in PVAm gel under certain conditions.
\end{abstract}

KEY WORDS Poly(vinylamine) / Viscosity Behavior / Poly(vinylamine) Gel / Swelling-Contraction Behavior / Chemo-mechanical Material / Phase Transition /

Recently, we have investigated the chelating properties of polyamines having different micro-structures. ${ }^{1-3}$ Polyamines examined are poly(vinylamine) (PVAm), ${ }^{3}$ poly(allylamine) (PAAm), ${ }^{1}$ linear and branched poly(ethylenimines) (LPEI and BPEI, respectively), ${ }^{2}$ which provide a full set of primarily different micro-structures for amine functional groups. ${ }^{2}$ During the course of these studies we have<smiles>CCC(N)CC(N)CC(C)N</smiles>

PVAm<smiles>CNCCNCCNC</smiles>

LPEI

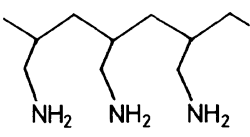

PAAm<smiles>CNCCN(CCN)CCNC</smiles>

BPEI paid attention on the viscosity behaviors of the polyamines in connection with the effects of the polymers' conformation on the chelating abilities. ${ }^{1-3}$ Now, we have found a dramatic viscosity change of PVAm, which is due to the specific micro-structure of PVAm having the primary amino group linked directly to the main chain. This viscosity behavior has explored us to develop a new gel derived from PVAm for a chemo-mechanical material. The PVAm gel swells and contracts in a very large extent with respect to changes of $\mathrm{pH}$, ionic strength of a neutral salt $(\mathrm{KCl})$, and cupric ion concentration. The gel has a cationforming group, which constitutes a sharp contrast to the well-known gels having an anionforming group such as poly(acrylic acid) and polý(methacrylic acid). ${ }^{4,5}$

\section{EXPERIMENTAL}

\section{Materials}

Two PVAmHCl samples prepared by radi- 
cal polymerization of $\mathrm{N}$-vinylformamide followed by acidic hydrolysis ${ }^{6}$ were supplied from Mitsubishi Kasei Co., Tokyo. The ${ }^{1}$ H NMR spectrum of.PVAmHCl showed no signal due to formyl proton $(\delta 8.1)$; the amount of $N$ formyl group in PVAmHCl was less than $1 \%$, if any. The $\eta_{\mathrm{sp}} / c$ values of the two samples were 0.33 and 3.23, respectively, measured in $1 N$ $\mathrm{NaCl}$ aqueous solution with $c=0.1 \mathrm{~g} \mathrm{dl}^{-1}$ and the number-average molecular weights of these samples are estimated as $1.0 \times 10^{4}(\mathrm{PVAm}-1)$ and $8.0 \times 10^{5}$ (PVAm-80), respectively, according to the literature. ${ }^{7}$

\section{Preparation of Gel}

The gels were prepared by using $3.5 \mathrm{~g}$ of PVAm and $1.0 \mathrm{~g}$ of a bis-epoxide, nonaethylene glycol diglycidyl ether ${ }^{1,8}$ as a crosslinking agent. The $3.5 \mathrm{ml}$ of $2.11 \mathrm{moll}^{-1}$ PVAm solution was mixed with the $0.7 \mathrm{ml}$ of the bisepoxide $\left(0.164 \mathrm{~mol}^{-1}\right)$, and then transferred to a glass mold, which was allowed to stand for $48 \mathrm{~h}$ at room temperature to give $2 \mathrm{~mm}$ thick of the transparent gel. The plate thus prepared was immersed in the distilled water at room temperature for several days and cut into strips
$10 \times 10 \times 2 \mathrm{~mm}$ in size. All the gel samples used in this study was prepared by using PVAm-80.

\section{Measurements}

The reduced viscosity of polymer solutions was measured with an Ubbelohde viscometer at various $\mathrm{pH}$ values at $25^{\circ} \mathrm{C}$ with varying the ionic strength of a neutral salt $\mathrm{KCl}$. The $\mathrm{pH}$ was adjusted by using aqueous $\mathrm{HCl}$ and $\mathrm{NaOH}$ solutions. All measurements were performed under $\mathrm{CO}_{2}$-free conditions.

\section{RESULTS AND DISCUSSION}

\section{Viscosity Behavior of PVAm}

Figure 1 shows the relationship between the reduced viscosity $\left(\eta_{\mathrm{sp}} / c\right)$ and $\mathrm{pH}$ for aqueous solutions of PVAmHCl-1 (Figure 1(a)) and PVAmHCl-80 (Figure 1(b)) with the various ionic strength $\left(\mu=0,0.01,0.1\right.$, and $1.0 \mathrm{moll}^{-1}$ with $\mathrm{KCl}$ ). A relatively steep peak appears for the PVAmHCl-1 sample at $\mathrm{pH} \approx 3$ in all cases of ionic strength, except $\mu=1.0 \mathrm{moll}^{-1}(\mathrm{KCl})$. For the PVAm sample, the degree of ionization is 100 percent around $\mathrm{pH} 3$, i.e., all the amino groups attached to the polymer chain
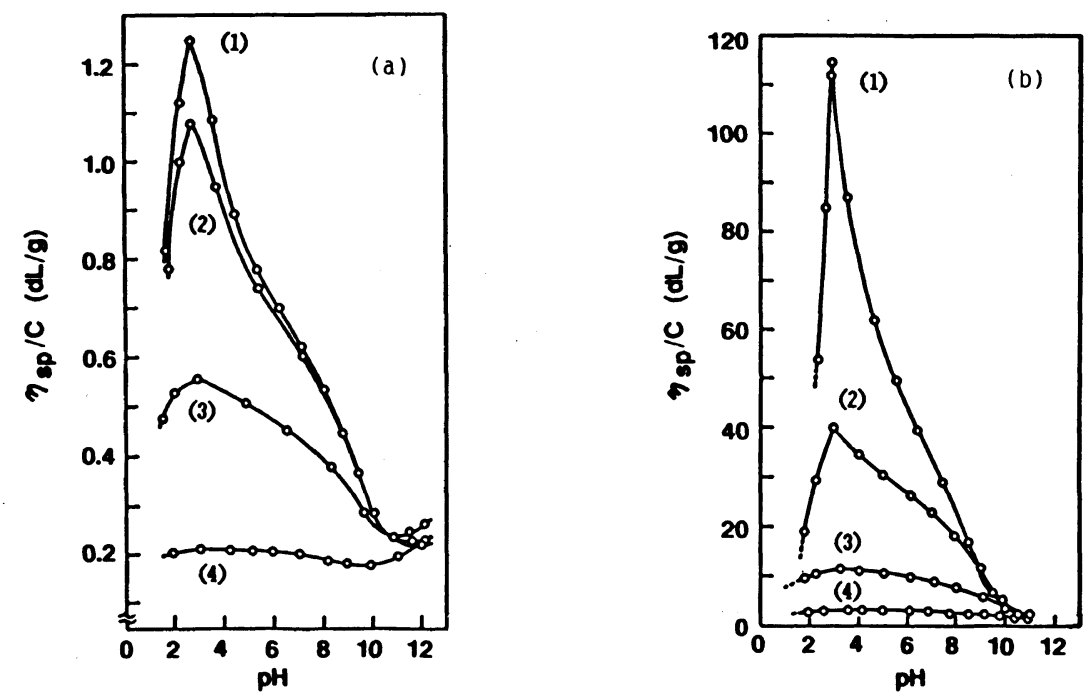

Figure 1. (a) $\eta_{\mathrm{sp}} / c-\mathrm{pH}$ relationships of PVAm- 1 at $25^{\circ} \mathrm{C}$ in water: $c=1.0 \mathrm{~g} \mathrm{dl}^{-1}$; (1) $\mu=0$, (2) 0.01 , (3) 0.1 , and (4) $1.0 \mathrm{moll}^{-1}(\mathrm{KCl})$. (b) $\eta_{\mathrm{sp}} / c-\mathrm{pH}$ relationships of PVAm- 80 at $25^{\circ} \mathrm{C}$ in water: $c=0.2 \mathrm{~g} \mathrm{dl}^{-1}$; (1) $\mu=0$, (2) $0.01,(3) 0.1$, and (4) $1.0 \mathrm{moll}^{-1}(\mathrm{KCl})$. 
are protonated. ${ }^{3}$ Thus, polymer chains take the most stretched structure in this $\mathrm{pH}$ region because of the electrostatic repulsion among neighboring ammonium groups. On the other hand, in regions of $\mathrm{pH}>3$ and $\mathrm{pH}<3$, the value of the reduced viscosity decreased dramatically since the repulsion is relaxed and the flexibility of chain is enhanced due to the neutralization of ammonium groups (at $\mathrm{pH}>3$ ) and to the increasing of the counterion $\left(\mathrm{Cl}^{-}\right)$concentrations (at $\left.\mathrm{pH}<3\right)$. The viscosity behaviors of PVAmHCl-80 are almost similar to those of PVAmHCl-1 over the wide range of $\mathrm{pH} 2-12$ in all cases of ionic strength. However, the value of the viscosity for PVAmHCl-80 at $\mathrm{pH} \approx 3$ in the case of $\mu=0$ is approximately 90 times larger than that of PVAmHCl-1. For PVAmHCl-80, the value of the viscosity at $\mathrm{pH} \approx 3$, at which the degree of ionization reaches $100 \%$, is nearly 100 times larger than that at $\mathrm{pH} 10-11$. The similar behavior was also observed in the presence of a salt $\mathrm{KCl}$ with $\mu=0.01,0.1$, and 1.0 , respectively.

Figure 2 indicates the effects of a heavymetal ion $\left(\mathrm{Cu}^{2+}\right)$ on the viscosity. Cupric ion clearly brought about the viscosity decrease, which is explained by the conformation change due to the chelate formation of $\mathrm{Cu}^{2+}$ with the amino group of PVAm.

\section{Swelling-Contraction Behavior of PVAm Gel}

In order to take advantage of this large viscosity change due to the different chain conformation depending on the changes of $\mathrm{pH}$, neutral salt concentration, and heavymetal ions, a PVAm gel has been prepared and its swelling-contraction behaviors have been investigated under various conditions to apply it for a chemo-mechanical material. The PVAm gel has been obtained by crosslinking PVAm with a bis-epoxide, nonaethylene glycol diglycidyl ether. ${ }^{1,8}$

The degree of volume swelling $Q$ of the gel is defined as following:

$$
Q=\left\{\left(V / V_{\mathrm{o}}\right)-1\right\} \times 100[\%]
$$

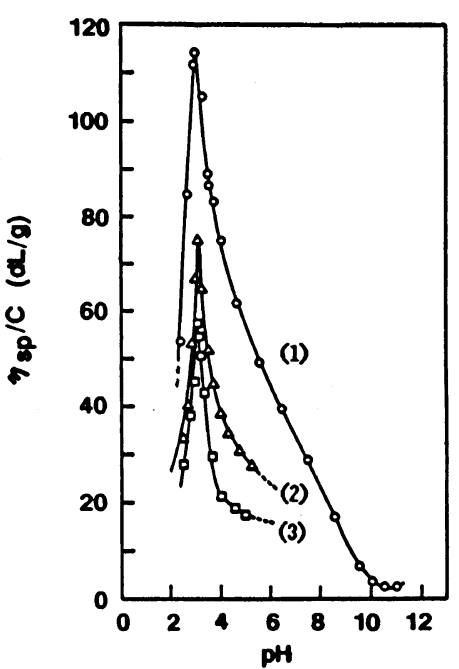

Figure 2. $\eta_{\mathrm{sp}} / c-\mathrm{pH}$ relationships of PVAm- 80 at $25^{\circ} \mathrm{C}$ in water in the presence of $\mathrm{Cu}^{2+}\left(\mathrm{CuCl}_{2}\right): \mathrm{C}=0.2 \mathrm{~g} \mathrm{dl}^{-1}$; (1) $\left[\mathrm{Cu}^{2+}\right]=0$, (2) $\left[\mathrm{Cu}^{2+}\right]=4.0 \times 10^{-4} \mathrm{moll}^{-1}$, and (3) $\left[\mathrm{Cu}^{2+}\right]=1.0 \times 10^{-3} \mathrm{moll}^{-1}$.

where, $V_{0}$ and $V$ are the volume of the gel before and after swelling, respectively. The term of $V / V_{0}$ can be expressed as $\left(A / A_{0}\right)\left(V / V_{0}\right)^{1 / 3}$ under the conditions of isotropic swelling, where $A_{0}$ and $A$ are the areas of the plate-like gel before and after swelling, respectively. Thus, eq 1 is rewritten as follows

$$
Q=\left\{\left(A / A_{0}\right)^{3 / 2}-1\right\} \times 100[\%]
$$

In this study, the degree of volume swelling of the gel under various conditions was calculated from eq 2 .

Figure 3 shows the dependency of the volume swelling $Q$ on $\mathrm{pH}$ for PVAm gel. The respective $Q$ value was determined after the gel volume reached constant in a freshly prepared solution of a certain $\mathrm{pH}$ value (normally, several hours), and then, the $\mathrm{pH}$ value was recorded. When $\mathrm{pH}$ changes from the base to acid region (from $\mathrm{pH} 12$ to 1 ), the gel takes the most swollen state at around $\mathrm{pH} 3$. In this $\mathrm{pH}$ region, the degree of volume swelling $Q$ is about $2000 \%$. In the range of $\mathrm{pH}$ below 3 , however, the gel began to contract and reached the $Q$ value of $350 \%$ around $\mathrm{pH} 1$. The above 


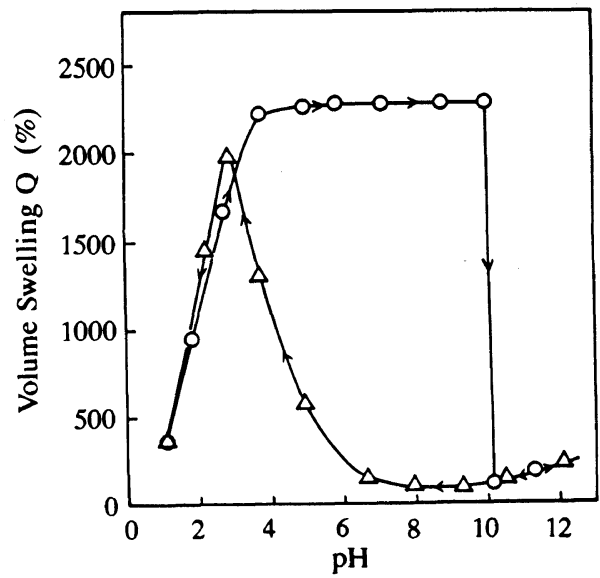

Figure 3. Dependency of the volume swelling $Q$ on $\mathrm{pH}$ for PVAm gel.

results are nearly similar to the viscosity behavior for PVAm solution (see Figure 1).

With the $\mathrm{pH}$ change from $\mathrm{pH} 1$ to 12 , the swelling-contraction behaviors of the gel are reversible in the regions of $\mathrm{pH}<3$ and $\mathrm{pH}>10$. In the range between $\mathrm{pH} 3$ and 10 , however, the gel showed an irreversible behavior and a phase transition occurred at $\mathrm{pH}$ 10 (Figure 3). It was reported that a phase transition phenomenon is observed in some gels. ${ }^{9-12}$ Tanaka et al. ${ }^{13-15}$ reported that the polymer network of certain acrylamide gels undergoes a discrete transition in equilibrium volume with changes of solvent composition and/or of temperature. They also demonstrated by using an acrylamide gel containing a portion of carboxylic acid group that the ionization of the acid in the polymer gel plays an essential role in the phase transition. ${ }^{16}$ As mentioned in the viscosity behavior for a PVAm sample, the degree of ionization of amino groups attached to the main chain is $100 \%$ around $\mathrm{pH} 3$ reached zero at $\mathrm{pH} 10-11$. Therefore, it is reasonable to assume that the difference in the degree of neutralization between the acidic and basic regions affects significantly on the hysteresis behavior of the swelling-contraction of the gel, that is, charged groups attached to the network play an essen-

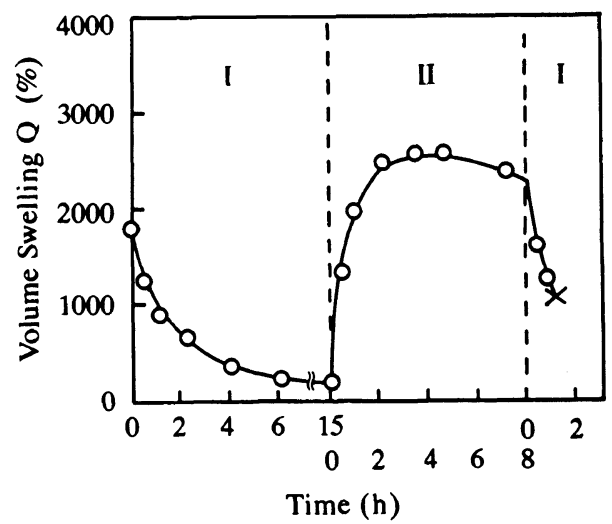

Figure 4. Swelling-Contraction behaviors of PVAm gel in $0.01 N \mathrm{NaOH}$ (region I) and in $0.01 \mathrm{~N} \mathrm{HCl}$ (region II). The sign $\times$ means breaking of the gel.

tial role in this behavior. The reasonable explanation for this complicated behavior of the present cationic type gels needs further studies.

The swelling-contraction behaviors of PVAm gel in $0.01 N \mathrm{NaOH}$ and $0.01 N \mathrm{HCl}$ solutions are shown in Figure 4. At the first stage, the gel was immersed in $0.01 \mathrm{~N} \mathrm{HCl}$ solution, and then after equilibrium was reached, the swollen gel was transferred into $0.01 \mathrm{~N} \mathrm{NaOH}$ solution (region I). In the region I, the swollen gel began to shrink and the equilibrium state was attained after $15 \mathrm{~h}$. This contracted gel was immersed again in $0.01 \mathrm{~N}$ $\mathrm{HCl}$ solution (region II), and then the gel began to swell until $2500 \%$ in $Q$ value. The swelling-contraction behavior in $\mathrm{pH}$ change could not be repeated because of the occurrence of phase transition as observed in Figure 3.

Figure 5 shows the dependency of the volume contraction ratio $Q_{\mathrm{A}} / Q_{\mathrm{B}}$ on the concentration of neutral salt $(\mathrm{KCl})$ solution at $\mathrm{pH}$ 3 for PVAm gel, where $Q_{\mathrm{A}}$ and $Q_{\mathrm{B}}$ are the degree of volume swelling of the gel after and before immersing in various concentrations of the $\mathrm{KCl}$ solution. All of the gel was swollen in $0.01 \mathrm{~N} \mathrm{HCl}$ solution prior to the experiment. The gel began to contract at the $\mathrm{KCl}$ concentration of $10^{-4} \mathrm{moll}^{-1}$ and the striking shrinkage was achieved at the concentration 


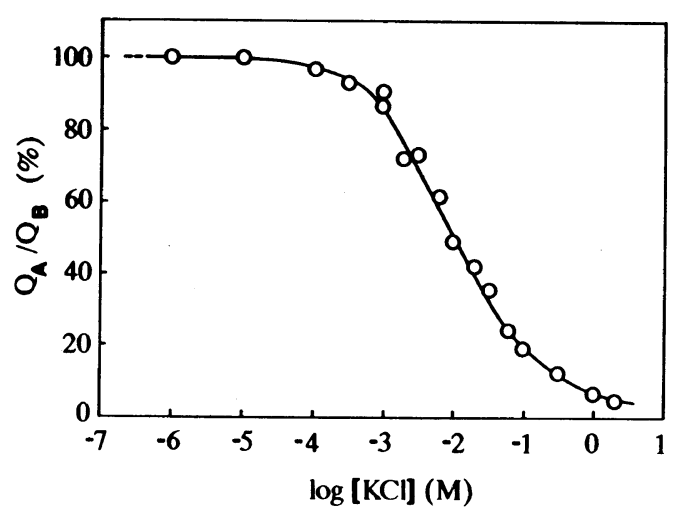

Figure 5. Dependency of the swelling-contraction ratio $Q_{\mathrm{N}} Q_{\mathrm{B}}$ on the concentration of $\mathrm{KCl}$ at $\mathrm{pH} 3$ for PVAm gel.

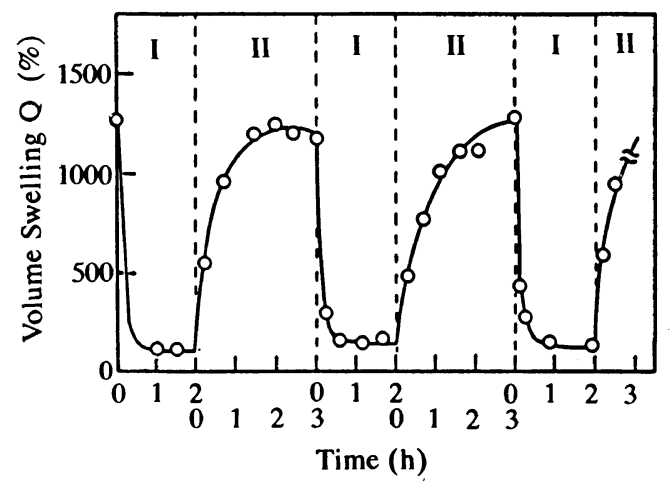

Figure 6. Effect of salt on swelling-contraction behaviors of PVAm gel in $1.0 \mathrm{moll}^{-1} \mathrm{KCl}$ (region I) and in $0.01 \mathrm{~N} \mathrm{HCl}$ (region II).

around $1.0 \mathrm{moll}^{-1}$. Thus, in Figure 6, the effect of salt on swelling-contraction behaviors of the PVAm gel was investigated in $1.0 \mathrm{moll}^{-1} \mathrm{KCl}$ solution. In region $\mathrm{I}$, the gel swollen in $0.01 \mathrm{~N} \mathrm{HCl}$ solution was immersed in a $1.0 \mathrm{moll}^{-1} \mathrm{KCl}$ solution. In this case, the equilibrium was reached after $1 \mathrm{~h}$; as can be seen from Figures 5 and 6 , the gel in a $\mathrm{KCl}$ solution reached to equilibrium more rapidly than in a basic solution. The shrinked gel was again immersed in $0.01 \mathrm{~N} \mathrm{HCl}$ solution to swelling (region II). This swelling-contraction cycle can be repeated several times without the destruction of the gel.

Figure 7 shows the effect of chelation on

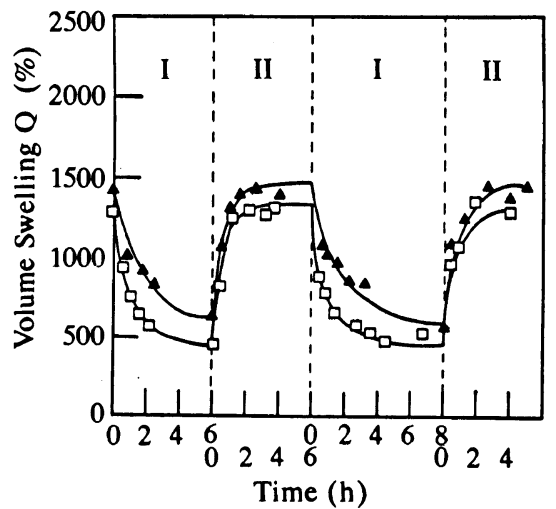

Figure 7. Effect of chelation on swelling-contraction behaviors of PVAm gels in $\mathrm{Cu}^{2+}\left(\mathrm{CuCl}_{2}\right)$ solutions of $0.005 \mathrm{moll}^{-1}$ (pH 5.0) (- - - ) and $0.01 \mathrm{moll}^{-1}$ (一 $\square$-) (region I), and in $0.01 \mathrm{~N} \mathrm{HCl}$ (region II).

swelling-contraction behaviors of PVAm gels in 0.005 and $0.01 \mathrm{moll}^{-1} \mathrm{Cu}^{2+}$ solutions. The experimental method was similar to those of Figures 5 and 6. A relatively fast response was attained by using the $\mathrm{Cu}^{2+}$ solution and the difference of concentration in the metal ion was observed in swelling-contraction behavior of PVAm gel. In the region I, the gel contracts due to the chelate-formation with $\mathrm{Cu}^{2+}$ ions. In $0.01 \mathrm{~N} \mathrm{HCl}$ solution, the $\mathrm{Cu}^{2+}$ ions are liberated and the gel swells again by the protonation of amino groups. In these cases, the swelling-contraction behavior was repeated several times.

Acknowledgments. S. K. is indebted to Grant-in-Aid for Scientific Research on Priority Area of "Macromolecular Complex" (No. 62612502 and 63612502) from the Ministry of Education, Science, and Culture of Japan for partial support of this study. We acknowledge the gift of two PVAm samples from Mitsubishi Kasei Co., Tokyo.

\section{REFERENCES}

1. S. Kobayashi, M. Tokunoh, T. Saegusa, and F. Mashio, Macromolecules, 18, 2357 (1985).

2. S. Kobayashi, K. Hiroishi, M. Tokunoh, and T. Saegusa, Macromolecules, 20, 1469 (1987). 
3. S. Kobayashi, K-D. Su, and Y. Shirokura, Macromolecules, 22, 2363 (1989).

4. W. Kuhn and A. Katchalsky, Bull. Soc. Belg., 57, 421 (1948); Helv. Chim. Acta., 31, 1994 (1948).

5. W. Kuhn, Experimentia, 5, 318 (1949); A Katchalsky, Experimentia, 5, 319 (1949).

6. K. Itagaki, T. Ito, K. Ando, and J. Watanabe, Jpn. Kokai 61-51007 (March 13, 1986) (to the Mitsubishi Kasei Co., Tokyo).

7. C. J. Bloys van Treslong and C. F. Morra, J. Royal Netherlands Chem. Soc., 94, 101 (1975).

8. S. Kobayashi, T. Tanabe, T. Saegusa, and F. Mashio, Polym. Bull., 15, 7 (1986).

9. T. Tanaka, Phys. Rev. Lett., 40, 820 (1978).

10. H. L. Frisch and S. Fesciyan, J. Polym. Sci., Polym.
Lett. Ed., 17, 309 (1979).

11. C. B. Post and B. H. Zimm, Biopolymers, 18, 1487 (1979).

12. G. Swislow S.-T. Sun, I. Nishio, and T. Tanaka, Phys. Rev. Lett., 44, 796 (1980).

13. T. Tanaka, S. Ishiwata, and C. Ishimoto, Phys. Rev. Lett., 38, 771 (1977).

14. T. Tanaka, L. O. Hocker, and G. B. Benedek, J. Chem. Phys., 59, 5151 (1973).

15. T. Tanaka, D. Fillmore, S-T. Sun, I. Nishio, G. Swislow, and A. Shah, Phys. Rev. Lett., 45, 1636 (1980).

16. D. Nicoli, C. Young, T. Tanaka, A. Pollak, and G. Whitesides, Macromolecules, 16, 887 (1983). 